\title{
The Exploration and Practice for the Mode of School-Enterprise Cooperative Education of "Promoting Education through Industry and Integrating Industry and Education"-A Case Study of Shanghai Publishing and Printing College
}

\author{
Jiaying Zheng ${ }^{\circledR}$ \\ Shanghai Publishing and Printing College, Shanghai, China \\ Email: 398059308@qq.com
}

How to cite this paper: Zheng, J.Y. (2019) The Exploration and Practice for the Mode of School-Enterprise Cooperative Education of "Promoting Education through Industry and Integrating Industry and Education"-A Case Study of Shanghai Publishing and Printing College. Journal of Service Science and Management, 12, 464-474.

https://doi.org/10.4236/jssm.2019.123032

Received: March 25, 2019

Accepted: April 25, 2019

Published: April 28, 2019

Copyright $\odot 2019$ by author(s) and Scientific Research Publishing Inc. This work is licensed under the Creative Commons Attribution International License (CC BY 4.0).

http://creativecommons.org/licenses/by/4.0/

\section{(c) (i) Open Access}

\begin{abstract}
School-enterprise cooperation, as the name suggests, is a cooperative model established by schools and enterprises. The cooperation between schools and enterprises is conducive to the win-win development of enterprises and schools. In recent years, although the cooperation between schools and enterprises has been developed rapidly, there are also some problems, such as the weak cooperation and the large cultural differences between schools and enterprises and the imperfect policies and regulations, which hindered the further development of school-enterprise cooperation. Shanghai Publishing and Printing College has accumulated relatively rich experiences in the process of school-enterprise cooperation, and gradually formed a useful reference to solve the problems in the process of school-enterprise cooperation. According to the need of research, this paper will adopt case study method.
\end{abstract}

\section{Keywords}

Industry and Education Integrating, The Mode of School-Enterprise Cooperative Education, Exploration and Practice

\section{Introduction}

In the past ten years, with the rapid development of China's economy and society, the demand of residents for cultural consumption is increasing day by day. 
As an important market of cultural consumption, the great demand of film and television media breeds and generates enormous market opportunities for the film and television industry. So, the talents of film and television are becoming more and more popular and professional in employment market. In 2013, in this context, the Shanghai Publishing and Printing College founded the Department of Film and Television Art combined with their own professional characteristics. At the beginning of its establishment, this department faced many problems, such as the shortage of teachers, a lack of equipment and imperfect personnel training mechanism, etc., which directly affected the sustainable development of personnel training in film and television. In order to solve the problems existing in the process of professional development, this department actively carried out school-enterprise cooperation, and strengthened its own construction and development by introducing enterprise support. It gradually formed the mode of school-enterprise cooperative education of "promoting education through industry and integrating industry and education".

School-enterprise cooperation, as its name implies, is a mode of cooperation between schools and enterprises. School-enterprise cooperation is generally recognized as the technical cooperation between enterprises and universities, which is based on the cooperation between enterprises as technology demanders and universities as technology suppliers. Because universities have advantages in scientific research, and enterprises have advantages in market operation, school-enterprise cooperation can give full play to the comparative advantages of universities and enterprises, and can accelerate the commercialization process of scientific research achievements in universities, and promote the transformation and upgrading of enterprises [1]. The understanding of the concept of school-enterprise cooperation should not be confined to technical cooperation. The real role of school-enterprise cooperation should be to improve the quality of personnel training. At present, the social competition is fierce, as well as the education industry. If the talents trained by universities cannot be universally recognized by the society, it will be a great negation of their teaching results. Therefore, in order to pursue their own development and grasp the quality of education, universities often adopt the way of cooperation with enterprises to cultivate talents for enterprises, with a focus on the practicality and effectiveness of personnel training. For enterprises, the rapid development is integrated with the support of technology and the construction of talent team, so it also needs to rely on the resources of universities to obtain the support of technologies and talents to be invincible in the fierce market competition. The establishment of school-enterprise cooperation mechanism is conducive to the win-win development of enterprises and schools. However, due to the different natures of enterprises and schools themselves, many common problems arise in the process of the cooperation. In detail, the former is the main body of the market, and is for the purpose of making profits, while the latter is the educational institution, and is for the purpose of educating people. 


\section{Major Problems in Training Collaborative Talents between Schools and Enterprises}

At present, school-enterprise cooperation has become an important way to realize industrial innovation in developed countries. However, from our country's situation, although the school-enterprise cooperation has achieved a rapid development in recent years, the current level of school-enterprise cooperation in China is not high overall, and there is no a good docking [2] between them. At present, the main factors affecting the further development of school-enterprise cooperation are as follows:

\subsection{The Insufficient Strength in School-Enterprise Cooperation}

At present, although school-enterprise cooperation has become an important direction for the development of many universities, compared with European and American countries, our country's strength of school-enterprise cooperation is not strong enough. Many universities often focus on signing agreements of cooperation framework, pay attention to news publicity, but do not care about the substantive changes that school-enterprise cooperation can bring to school education. Although the performance of the school is on contrary, most enterprises have a stronger intention to cooperate. They hope to get the support of the school's technology and talents to expand their business to maximize their profits. They also hope to use the platform of the school to strengthen external publicity, and enhance their visibility. However, as partners, schools do not know how to cooperate with enterprises in a real sense, so most enterprises only provide places for students to practice in school-enterprise cooperation, and do not fully participate in the whole process of personnel training; enterprises sometimes suspect that newly graduated students are weak in hands-on ability, lack of practical experience and enthusiasm, so there is no much interests for them to employ graduates; from learning in their school to practice in an enterprise, then to work in an enterprise, students need to complete the transformation from school students to enterprise staff. There are great differences in the management mechanism and cultural construction between schools and enterprises, however, which will inevitably affect this transformation [3], and directly lead to the difficulty for school-enterprise cooperation to develop in a deeper direction.

\subsection{Quite Different Culture of School-Enterprise}

There is a large cultural difference between universities and enterprises, which is an important factor in the close cooperation between schools and enterprises. Universities are educational institutions. All of their work is centered on educating people. The motivation of university teachers' work comes from students and peer recognition for their own teaching and research, thus they could obtain higher professional titles. For the enterprise, the main body of the market economy, it in face of fierce market competition. So, it must constantly improve its core competitiveness, and take obtaining profits as the focus of all the work of 
the enterprise. In such an environment, the motivation of employees is to enhance the competitiveness of products, to win more profits for the company, so as to get more remuneration. At present, the cultural differences between schools and enterprises have been significantly weakened in developed countries. [4] In China, although a series of reforms have been carried out in recent ten years, the cultural differences between schools and enterprises are still very large. One prominent manifestation is that there is still a lack of clear market orientation in the evaluation system of professional titles in universities. For a long time, the market value of scientific research achievements has been neglected in the evaluation of these achievements, which leads to the fact that scientific research achievements are not market-oriented, but purely pursuing academic value and derailing from reality, and ultimately leads to the insufficiency technology supply of universities for enterprises. The evaluation of teachers' professional title and performance appraisal are not closely related to school-enterprise cooperation, which is the main reason why university teachers lose interests and motivations in school-enterprise cooperation [5].

\subsection{Imperfect Policies and Regulations}

At present, there is no special law to stipulate the rights and obligations of both partners, which easily leads to a reasonable solution to the problems arising in the process of school-enterprise cooperation. Compared with enterprises, schools, as institutions, need to shoulder more social responsibility. So disputes between the two sides easily bring more burdens to schools, which easily throws cold water on the enthusiasm and initiative of schools in the process of school-enterprise cooperation. The success of foreign school-enterprise cooperation in training talents is due to the relatively perfect laws and regulations as a guarantee. The corresponding laws and regulations have made comprehensive provisions on the responsibility, safeguard measures and management mechanism of schools and enterprises in school-enterprise cooperation. However, in China, on strengthening school-enterprise cooperation to promote talent cultivation, the legislation is relatively lagging behind, and the interests of both sides are not adequately protected in the process of school-enterprise cooperation in talent cultivation [3]. Therefore, in order to reduce the conflicts and disputes between the two sides of school-enterprise cooperation, the national legislature should legislate on this aspect, so as to be more conducive to the educational activities of universities, and to promote the healthy development of enterprises.

\section{Case Study on Talent Cultivation by School-Enterprise Cooperation of Film and Television Art Department}

In the process of school-enterprise cooperation, the Department of Film and Television Art has carried out many beneficial attempts in order to maximize the support of enterprise resources, and to promote the cross-domain development.

It gradually formed the model of school-enterprise cooperative education of 
"promoting education through industry, integrating industry and education".

\subsection{Introduction of Film and Television Art Department of Shanghai Publishing and Printing College}

Shanghai Publishing and Printing College was established in 1953, which is the first publishing and printing college in China, the cradle of China publishing and printing education, a characteristic college jointly built by State Press and Publication Administration (original General Administration of Press and Publication) and Shanghai Municipal Peoples Government. It is an Excellent Construction Unit of 100 national demonstrative key higher vocational colleges, a construction unit of national higher vocational education teaching resource bank, one of the first pilot units of construction of modern university system in Shanghai. In the past 60 years, it has cultivated more than 60,000 technological backbones of different levels and senior management staff for China's publication and printing industry. Our colleges are confirmed as "national printing and publication talents cultivation base" by State Administration of Press, Publication, Radio and Television.

The Film and Television Art Department was established in 2013, a department combining art and technology established by Shanghai Publishing and Printing College to adapt to the development of culture industry at that time . It is positioned on the basis of the rule of school-running of film and television art, adheres to rigorous and scientific major construction and teaching management, combines with the development of Shanghai economy and culture, especially the development requirements of film and television industry, optimizes major structure continuously, complete major system, expand employment channels and obtains great achievements. The Film and Television Department now has 8 major directions, including production of radio, film and television programs, film and television directing, film and television multimedia technology, digital media art design (multimedia design and production), advertising design and production (film and television advertising), drama film and television Performance, advertising design and production (Sino-US operation), radio film and television production (Sino-French cooperation).

\subsection{Method I Invite Enterprises with School-Enterprise Cooperation for Planning and Constructing Disciplines to Realize Promoting Education through Industry}

On the basis of substantial labor input and material input, after several years of development, the professional school running level of the Film and Television Art Department has improved outstandingly. After the development in recent years, the professional level of the Department of Film and Television Arts has been significantly improved. Nevertheless, the development of the Department of Film and Television Art still lags far behind the old film and television colleges. In order to further improve the professional construction level of the De- 
partment of Film and Television Art, and to realize the leap-forward development of this Department, the Department of Film and Television Art decided to apply for the major of image archives. As a new subject, it gathers the essence of media, archives, art and archives management, which is not included in The Catalogue of Undergraduate Majors in General Colleges and Universities and The Catalogue of Specialties in Higher Vocational Education in General Colleges and Universities.

The Department of Film and Television Art actively applies the image archives major, but it does not have much accumulation for the profession. In order to carry out professional planning more reasonably, this department decided to invite the school-enterprise cooperation unit of Shanghai Yulong Guangbi Culture Investment Co., Ltd. to participate in the planning and construction of the image archives profession, which is a breakthrough in the past school-enterprise cooperation model. In the past, in the process of school-enterprise cooperation, although the company understands the developments and trends of the industry, it does not participate in the professional planning and construction of the school. It often makes the professional construction of the school out of line with the actual needs of the market. The "talent" cultivated by the school can not only keep up with the trend of the times, but also cannot be valued by enterprises, resulting in huge waste of manpower and material resources. In view of this kind of situation, the Department of Film and Television Art has made a decisive attempt. Shanghai Yulong Guangbi Culture Co., Ltd. is a leading enterprise in China's image archives industry. It is particularly aware of the development of the image archives industry and the demand for talents. Although the image archives industry is not included in The Catalogue of Undergraduate Majors in General Colleges and Universities and The Catalogue of Specialties in Higher Vocational Education in General Colleges and Universities, as an emerging industry, image archives have developed extremely rapidly in recent years, and is in urgent need of a large number of resources and talent as a support. At present, no one institution in China has an image archives major, and there are extremely few talents in this major. The shortage of talents will definitely affect the healthy and orderly development of the industry. For that reason, in order to better build the image archives profession and do a good job in personnel training, the Department of Film and Television Art carefully listened to the suggestions of Shanghai Yulong Guangbi Culture Co., Ltd. during the application process of the image archives major, and many useful modifications were made extensively on the basis of the wide and in-depth discussion on professional planning and training programs. The Department of Film and Television Art emphasized "focus on integration", "fine technology" and "know the market" in the setting of image archives engineering, with the goal of cultivating "compound" talents. The participation of the company has approved the Department of Film and Television Art for the application of the image archives industry, and indirectly answered how the art disciplines cultivate the "applied" talents 
that truly urgent needed by the market in the orientation of "application-oriented" colleges. The company also believed that in the school-enterprise cooperation, this department will be able to have the image archives major, and to achieve its own leap-forward development in the near future.

The Department of Film and Television Art invited enterprises to build and plan disciplines and specialties, which expanded the scope and depth of school-enterprise cooperation, and achieved the goal of promoting education through industry. This is a useful attempt for this department in training talents through school-enterprise cooperation.

\subsection{Method II Co-Construct Practical Teaching Platform to Train and Select of Talents to Realize Promoting Education through Industry}

In the process of training skilled talents, it is necessary to carry out professional construction and planning in advance. Only in this way can we know the market information, and know what kind of talents enterprises are really needed, and talent training can be better carried out. In addition to professional construction and planning, the Department of Film and Television Art also introduced enterprise resources into talents selection and training to cultivate students' professional skills. In order to improve students' professional skills and innovative and entrepreneurial ability, this department conducted a cooperation with Shanghai Yulong Guangbi Cultural Investment Co., Ltd., so they jointly established a practical teaching platform- "Experimental Class of Image Archives with Innovation and Entrepreneurship" to train students.

In order to better train the students in this experimental class of image archives with innovation and entrepreneurship, the Department of Film and Television Art and Shanghai Yulong Guangbi Cultural Investment Co., Ltd. have made some innovations in all aspects of personnel training.

At present, China is in a critical period of transformation and development, and a large number of enterprises need skilled talents to rely on in order to realize the transformation from extensive development model to intensive model. In order to achieve this goal, the "experimental class of image archives with innovation and entrepreneurship" does not only take academic achievement as the sole criterion in the process of talent selection, but also takes students' solid professional knowledge, excellent operational skills, keen innovative thinking and deep pioneering ability into account. In the process of talent selection, it not only considers students' academic achievements, but also pays more attention to the cultivation of students' learning interests. For those students who has leaning branch phenomenon but also loves the image archives industry, this experimental class allocates a number of places to these students, hoping to take this opportunity to further improve their professional skills.

In personnel training, "experimental class of image archives with innovation and entrepreneurship" not only employs enterprise teachers to teach, but also regularly trains enterprise teachers in teaching methods. In addition, this expe- 
rimental class also sent school teachers to enterprises for professional learning. This experimental class agreed that the performance of both enterprise teachers and school teachers during the class of this experimental class was twice higher than their usual work's, so as to encourage teachers to participate in teaching activities. On this basis, this experimental class has made many beneficial attempts in the training mode for the characteristics of the students of the Department of Film and Television Art who have strong practical ability and poor theoretical level. A qualified skilled person needs not only to master skills, but also to master theory. Only by combining theory with skills can he/she be called an excellent person. In order to improve the teaching effect, this experimental class constantly explores interactive teaching mode, innovates personnel training mechanism, creates a "happy teaching" atmosphere, organically integrates situational teaching, case teaching, project teaching and other modes to promote students' learning theory and skills; after class, this experimental class encourages students to learn through micro-class teaching. The relaxed and lively teaching atmosphere of this experimental class is undoubtedly an organic adjustment to the busy work of enterprise teachers. Many enterprise teachers find a piece of unprecedented pleasure in the teaching process, which also stimulates their enthusiasm for teaching and educating.

On the basis of classroom theory teaching, the Department of Movie and Television Art pays more attention to students' practical education. In order to enhance the practical teaching skills of this experimental class, they carried out the initiative entrepreneurial tutorial system. Six senior pioneering tutors, including Shanghai Yulong Guangbi Culture Investment Co., Ltd., Yangpu Times and Hongkou News Media Center, were employed to teach this class. The class students were divided into six groups of editors, playwrights, filming, post-production, lighting and production teams, and each with a full-time tutor. Students form mixed teams to promote multi-professional practical teaching. The training program ranges from the preparation skills and basic qualities of employment to the practical observation of enterprises, and finally enters the post of enterprises. After graduation, students can directly get employment if they meet the technical requirements of enterprises.

Through the teaching of this experimental class, enterprise teachers can adjust the rhythm of life through relaxed and lively teaching activities, which can also stimulate their enthusiasm for teaching and educating, and deepen their understanding of the education industry. For school teachers, through enterprise learning, they can understand the industry dynamics, deepen their understanding of the market, and help them to carry out new teaching works in the future.

Through the study and practice of this experimental class, most of the students have improved their professional skills and strengthened their ideal and belief in the image archives industry. They hope that through their own efforts, they can achieve the ultimate goal of their career in the near future, and take their own actions to help the development of the image archives industry. Some students who usually do not perform well in school have also built up 
self-confidence, and gradually improved the phenomenon of leaning branch. They have repaid the recognition of school teachers and practice units with their excellent performance.

Although there are great cultural differences between schools and enterprises, it cannot hinder the organic combination of the two. First, schools are the main body of education, and enterprises can also be the main body of education. Second, an excellent enterprise, it can not only value the immediate interests, but also should have its own ideals and beliefs, and take the initiative to assume its social responsibility in order to have long-term development. Participation in educating people is also the social responsibility of enterprises. Third, a talented person should not only master professional skills, but also have his own ideals and beliefs, love his career, and start and finish well. In short, practice tells us that enterprises can participate in education, promote the development of the education industry, and realize the integration of industry and education.

\subsection{Method III Integrate Industry and School with the Basis of Building a Creative Park through Industry-University-Research Cooperation}

Institutions of higher learning are not only educational occasions, but also the birthplace of industrial development. At present, colleges and universities are mainly involved in the process of industrial development in the form of park construction. From this point of view, universities should not exclude cooperation with enterprises because of their own characteristics of educating people. Furthermore, in promoting the development of industry, the two have consistency. Besides, enterprises should not neglect the cooperation with schools for the purpose of making profits because the two also have consistency in the construction of the park.

In recent years, the construction of the park has increasingly become an important base for universities to carry out industry-university-research cooperation. Nowadays, all parts of the country are carrying out the construction work of the park in full swing. Although the building form and the area of the park may be different, there is one thing in common. These parks all pursue the development needs of local high-tech industries, basing on famous universities, integrating universities and local resources, and adopting the model of university science and technology park with co-construction of campus and land and multi-campus in one park, so as to promote the establishment of $\mathrm{R} \& \mathrm{D}$ platform in research and development and achievements transformation., incubation platform and industrialization base. Although the original intention of park construction is good, there are many problems in the process of implementation. For example, some university parks often do not plan reasonably according to the actual needs, but try to introduce so-called high-tech enterprises, excluding some non-high-tech enterprises. As a result, many science parks eventually become ghost cities, and do not achieve the purpose of local economic development. 
In order to avoid the appearance of an empty city in the park construction, Shanghai Publishing and Printing College has made bold innovations in the construction of the creative park on the basis of lacking of experience. The enterprises entering the creative park are not only high-tech enterprises, but also leading enterprises with professional characteristics. Shanghai Yulong Guangbi Cultural Investment Co., Ltd. is one of them. This college positioned the creative park as the incubation base for the development of the industry. By introducing leading enterprises with professional characteristics, cultivating downstream enterprises and promoting the growth and development of the overall scale of the industry, the development of the industry would in turn promote the quality of the creative park, attract more leading enterprises with professional characteristics. And a virtuous circle of the entrepreneurs and schools will eventually be realized, and the entrepreneurship park would be the innovation and entrepreneurship base of Shanghai's digital publishing media.

It is an example that the cooperation between the Department of Film and Television Art and Shanghai Yulong Guangbi Cultural Investment Co., Ltd. In order to promote the construction in the innovation and entrepreneurship base of Shanghai's digital media, they cooperated to build an incubator base for innovation and entrepreneurship of image archives, aiming to further enhance students' innovation and entrepreneurship ability. The company will establish the branch of this incubation base. On the one hand, it will consolidate and expand its own business. On the other hand, it will serve as a training base for students' innovation and business, and support business partners. At present, this company fully supports two students of the Department of Film and Television Art to start their own businesses. It is believed that the creative park of Shanghai Publishing and Printing College will become the birthplace of the national image archives industry in the near future.

Although there are great cultural differences between schools and enterprises, it cannot deny the consistency of the two in promoting industrial development. Conversely, the development of industry also promotes the improvement of the quality of personnel training, and forms a virtuous circle. The main reason why there are many barriers between enterprises and institutions of higher learning lies in the lack of appropriate forms of cooperation. There is no inevitable conflict between enterprise development and educating people themselves. Industry and education can be integrated and developed.

\section{Conclusions}

School-enterprise cooperation, as its name implies, is a mode of cooperation between schools and enterprises. School-enterprise cooperation is conducive to promoting the win-win development of enterprises and schools. In recent years, although the rapid development of school-enterprise cooperation, it also has some problems, such as weak school-enterprise cooperation, great cultural differences between schools and enterprises, imperfect policies and regulations, 
which hinder the further development of school-enterprise cooperation. The Department of Film and Television Art of Shanghai Publishing and Printing College has accumulated rich experiences in the process of school-enterprise cooperation, which can be used as a useful reference to solve the problems in the process of this cooperation.

Although there are great cultural differences between schools and enterprises, it cannot hinder the organic combination of the two. Schools are the main body of education, and enterprises can also be the main body of it. An excellent enterprise, it can not only value the immediate interests, but also should have its own ideals and beliefs, take the initiative to assume its social responsibility to have long-term development. The main reason why there are many barriers between enterprises and institutions of higher learning lies in the lack of appropriate forms of cooperation. There is no inevitable conflict between enterprise development and educating people.

\section{Conflicts of Interest}

The author declares no conflicts of interest regarding the publication of this paper.

\section{References}

[1] Guo, B., Xie, Z.Y. and Wu, H.F. (2003) Influencing Factors and Empirical Analysis of the Performance of Industry-University Cooperation. Scientific Research, 21, 140-147.

[2] Huang, C.C. (2007) School-Enterprise Alliance: Innovation Model of Industry-University Cooperation Organization in China. Zhejiang University, Hangzhou.

[3] Ma, H.C., Zhong, S.B. and Li, G.Z. (2013) Research of Personnel Training Mode and Mechanism Innovation in School-Enterprise Cooperation. Agricultural Science and Technology Management, 32, 92-95.

[4] Li, Z.W., Wang, D.Z. and Li, X.M. (2012) An Empirical Study on the Present Situation and Influencing Factors of School-Enterprise Cooperation: Taking Zhejiang Province as an Example. Science Progress and Countermeasures, 29, 150-154.

[5] Hu, E.H and Guo, X.L. (2002) Problems and Countermeasures in the Innovation of Industry-University-Research Cooperation in China. Scientific Management Research, 20, 69-72. 